\title{
High-angular-resolution camera coupled with an undulator source at the European synchrotron radiation facility high- brilliance beamline
}

\section{Citation for published version (APA):}

Diat, O., Bösecke, P., Lambard, J., \& Moor, de, P-PEA. (1997). High-angular-resolution camera coupled with an undulator source at the European synchrotron radiation facility high-brilliance beamline. Journal of Applied Crystallography, 30(5), 862-866. https://doi.org/10.1107/S0021889897001878

DOI:

10.1107/S0021889897001878

Document status and date:

Published: 01/01/1997

Document Version:

Publisher's PDF, also known as Version of Record (includes final page, issue and volume numbers)

\section{Please check the document version of this publication:}

- A submitted manuscript is the version of the article upon submission and before peer-review. There can be important differences between the submitted version and the official published version of record. People interested in the research are advised to contact the author for the final version of the publication, or visit the DOI to the publisher's website.

- The final author version and the galley proof are versions of the publication after peer review.

- The final published version features the final layout of the paper including the volume, issue and page numbers.

Link to publication

\footnotetext{
General rights

- You may freely distribute the URL identifying the publication in the public portal. follow below link for the End User Agreement:

www.tue.nl/taverne

\section{Take down policy}

If you believe that this document breaches copyright please contact us at:

openaccess@tue.nl

providing details and we will investigate your claim.
}

Copyright and moral rights for the publications made accessible in the public portal are retained by the authors and/or other copyright owners and it is a condition of accessing publications that users recognise and abide by the legal requirements associated with these rights.

- Users may download and print one copy of any publication from the public portal for the purpose of private study or research.

- You may not further distribute the material or use it for any profit-making activity or commercial gain

If the publication is distributed under the terms of Article $25 \mathrm{fa}$ of the Dutch Copyright Act, indicated by the "Taverne" license above, please 


\title{
NEW SMALL-ANGLE SCATTERING FACILITIES
}

J. Appl. Cryst. (1997). 30, 862-866

\section{High-Angular-Resolution Camera Coupled with an Undulator Source at the European Synchrotron Radiation Facility High-Brilliance Beamline}

\author{
O. DIAT, ${ }^{a} *$ P. BÖSECKE, ${ }^{a}$ J. LAMBARD ${ }^{b}$ AND P. P. E. A. DE MOOR ${ }^{c}$ \\ ${ }^{a} E S R F, B P 220,38043$ Grenoble CEDEX, France, ${ }^{b} C E A, C E N$ Saclay, SCM, BP125, F-91191 Gif-sur-Yvette CEDEX, \\ France, and ${ }^{C}$ Eindhoven University of Technology, LIC, PO Box 513/SH6.11a, 5600 MB Eindhoven, The Netherlands. \\ E-mail: diat@esrffr
}

(Received 22 August 1996; accepted 31 January 1997)

\begin{abstract}
The performance of a high-angular-resolution smallangle X-ray camera combined with an undulator source is presented in the form of examples.

\section{Introduction}

Recently, a high-angular resolution X-ray camera has been used in combination with the high-brilliance X-rays from an undulator source (Diat et al., 1995). We highlighted the advantage of a low-divergence X-ray beam that allows us to handle channel-cut crystals with highorder Bragg planes, i.e. crystals with narrow angular acceptances. Thus, one can increase the angular resolution and decrease the acquisition time, which are very important criteria for ultra-small-angle X-ray scattering experiments. It was pointed out that the angular resolution of the analysis should be comparable in both the vertical and the horizontal directions to avoid smearing of the measured scattering curves. In addition, the 'parasitic' tails [in $\left(2 \theta-2 \theta_{\mathrm{Bragg}}\right)^{-2}$ ] of the crystal rocking curves (Diat et al., 1995; Bonse et al., 1988; Pahl, 1990; Lambard et al., 1992; Chapman et al., 1992; Graf et al., 1981) give a relatively high background signal at small scattering angles and reduce the limit of performance of such a camera. Therefore, to increase the signal-to-noise ratio, the rejection rate, which is defined as the ratio between the remaining background for a given scattering angle and the maximum intensity of the related rocking curve, has to be improved. The X-ray camera is described in the first part of this article and the rocking-curve data and the smearing effect are discussed. In the second part, some raw data collected at the European Synchrotron Radiation Facility (ESRF) on the high-brilliance beamline $\mathrm{ID} 2$ are presented, showing the features and performance of the camera.
\end{abstract}

\section{Experimental set-up}

A schematic top view of the high-angular-resolution camera set-up is shown in Fig. 1. The first part of the

(C) 1997 International Union of Crystallography

Printed in Great Britain - all rights reserved camera coincides with the general optical part of the beamline, which is already designed and optimized for the small-angle X-ray scattering station in the second experimental hutch of the beamline (Bösecke, Diat \& Rasmussen, 1995; Bösecke \& Diat, 1997). It consists of an undulator source $(26 \mathrm{~mm}$ period) that provides a very intense and low-divergence white beam (V $20 \mu \mathrm{rad} \times \mathrm{H}$ $40 \mu \mathrm{rad}$ full width at half-maximum). Then, a first tworeflection (in the vertical direction) channel-cut $\mathrm{Si}(111)$ crystal $(C 1)$ is used as a monochromator. For our experiments, a wavelength of $1 \AA$ was selected with $\Delta \lambda / \lambda=3 \times 10^{-4}$. The beam is focused with a toroidal mirror on a focal point upstream of the detection point (with a demagnification ratio of 1:1). Sets of slits are installed at different positions to provide a 'clean' and collimated beam at the beginning of the second part of the camera. This second part, which is not permanent but which could be easily restored, is placed at the usual sample position for small-angle X-ray scattering (SAXS) experiments on $\mathrm{ID} 2$ (the high-brilliance beamline). This part consists first of a three-reflection channel-cut $\mathrm{Si}$ crystal (C2) using the 220 Bragg planes. Secondly, in order to analyse either the Bragg reflected beam or the scattered intensity from a sample, we use a set of two crossed analyser crystals. The first one, $C 3$, is also a

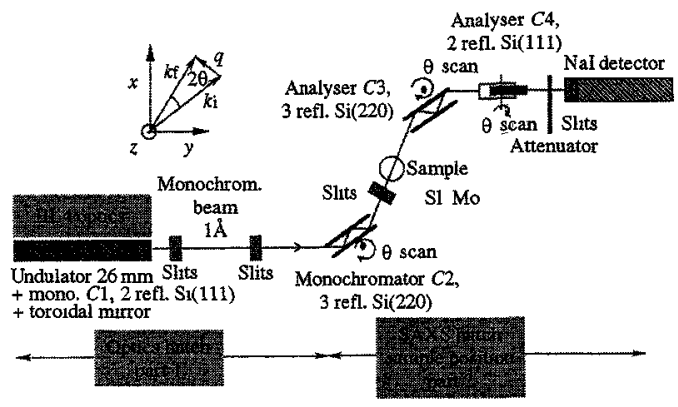

Fig. 1. Configuration of the experiment. The distance between the undulator and the camera (first part) is about $65 \mathrm{~m}$ and the camera length (second part) is $1 \mathrm{~m}$.

Journal of Applied Crystallography ISSN 0021-8898 (C) 1997 
three-reflection (in the horizontal plane) channel-cut $\mathrm{Si}(220)$ crystal and is used as the actual analyser; the second one, C4, a vertical two-reflection $\mathrm{Si}(111)$ crystal, is used as a collimator in the vertical direction in order to obtain a comparable angular resolution in both vertical and horizontal directions. The $C 2, C 3$ and $C 4$ crystals (cut and polished by A. Paul of the optics group at the ESRF) are mounted on in-house goniometers providing tilt and translation movements for positional and rotational adjustments. The angular resolution is $0.2 \mu \mathrm{rad}$ per motor step and the adjustment reproducibility of the rotations is $2 \mu \mathrm{rad}$. The goniometers also ensure that translations of the crystals are parallel. The beam stability is excellent (beam monitors are available) and therefore no realignment is required during the user experiment time (on average 2 or $3 \mathrm{~d}$ ).

Although the five-reflection option (i.e. five reflections option in $C 2$ and $C 3$ ) would give a better rejection rate (Diat et al., 1995; Lambard et al., 1992), we have kept the three-three reflection configuration in order not to decrease too much the photon flux and also to simplify the alignment procedure.

The detector is a scintillator with a $10 \mu \mathrm{m}$-thick NaI crystal that is less sensitive to the remaining harmonics, which are already partially removed by the mirror. It is connected to a single-channel analyser and behaves linearly over four decades. A set of aluminium foils with different thicknesses of between 0.5 and $5 \mathrm{~mm}$ can be inserted in the beam, just before the detection point, in order to cover the large detection dynamics over the total angular scattering range. In future, these attenuators will be placed upstream of the crystal $C 2$, so as to further reduce the beam intensity on the sample. To reduce sample X-ray damage, the development of the synchronization between a fast beam shutter and the detector is in progress.

\section{Rocking curve and smearing effects}

The monochromator $C 2$ response function, the rocking curve, can be measured by rocking the crystal $C 3$ around the vertical $z$ axis as described in Fig. 1. It corresponds to the correlation function of the reflection curves $R n(q)$ of both crystals, where $n$ is the number of reflections in each crystal (Dumond, 1937; Bonse \& Hart, 1965, 1966) and $q$ is the scattering vector. However, whatever the number $n$ of Bragg reflections in the channel-cut crystal, it was always observed that the parasitic tails following the power law $q^{-2}$ [or $\left(\theta-\theta_{\text {Bragg }}\right)^{-2}$ if we refer to the rocking angle] are superimposed on the expected theoretical curve (Diat et al., 1995; Bonse et al., 1988; Pahl, 1990; Lambard et al., 1992; Chapman et al., 1992; Graf et al., 1991). The curve (a) in Fig. 2 corresponds to the rocking curve of the crystal $C 2$ with only one analyser crystal $C 3$ and a $1 \mathrm{~mm}$ opening vertical slit (instead of the $C 4$ crystal and called configuration 1). We observe these parasitic tails following the power law $q^{-2}$ for which the origin is at this time not well understood (Diat et al., 1995; Pahl \& Bonse, 1995) but which seems not to be dependent on the crystal or on the experimental set-up (Arthur, 1996).

We focused our efforts on reducing the background and other parasitic scattering events as much as possible in order to achieve the best rejection rate $P$ for the smallangle X-ray scattering experiments. We obtain $P=10^{-6}$ at $q=10^{-3} \AA^{-1}$, which is two orders of magnitude less than that obtainable with an X-ray generator (Lambard et $a l .$, 1992). Therefore, we analysed the rocking curve again, but with two crossed analysers [configuration 2, see $(b)$ in Fig. 2]: the FWHM is the same (see the inset of Fig. 2) but the main difference is the large change in the slope of the scattering tails from $q^{-2}$ to $q^{-3}$, which is clearly visible on the $\log -\log$ plot.

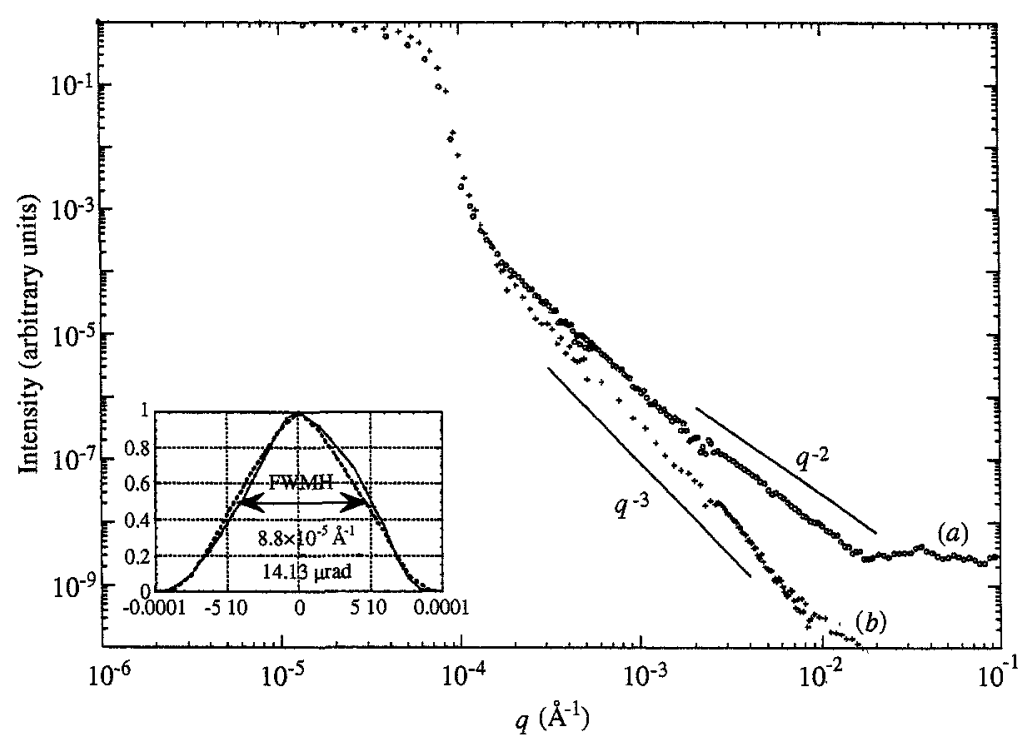

Fig. 2. $\log -\log$ plots of $(a)$ the rocking curve of the crystal $C 2$ with the crossed analysers $C 3$ and $C 4$, and $(b)$ the rocking curve of the crystal $C 2$ with one analyser $C 3$ and a vertical slit with an opening of $1 \mathrm{~mm}$ height. The inset corresponds to the $\ln$-in representation of the two rocking curves in order to compare the corresponding full widths at half-maximum. 
In the first configuration, the vertical resolution is defined by vertical slits placed in front of the detector, whereas in the second configuration it is defined by the acceptance of the crystal $C 4$. In other words, the detected scattered signal contains in the first case a large contribution of the scattering out of the horizontal plane that smears the real scattering at small and ultra-small scattering angles but that is eliminated by the crystal $C 4$ in the second case. Since the angular acceptance of the crystal $C 4$ is approximately 2000 narrower than that of the slits, the use of both crossed analysers requires a large photon flux (about $5 \times 10^{10}$ photons $\mathrm{s}^{-1}$ ) at the sample position, which is available on ID2. Moreover, no unfolding operations are necessary to analyse the raw data.

\section{Experimental examples}

We present two types of applications. The first concerns two types of silica materials and reveals the minimum scattering angle required in some SAXS experiments and the advantage of using crossed analysers. The second shows the benefit of the high-angular-resolution detection at larger scattering angles.

Silicas are materials with a wide variety of properties due to the large choice of possible preparation methods, and are used in many industrial applications, such as filter agents, filling materials, abrasive products and as catalyst carriers in heterogeneous catalysis, and so on. For example, different kinds of preparations, like hydrolyse-condensation-polymerization (Stöber type) or pyrogenation techniques, lead to different aggregation states. Their structures can be characterized on different scales by SAXS. Two scattering patterns on different silica systems are presented.

Fig. 3 corresponds to the scattering profile (dotted curve) of a solution of silica spheres (Stöber type, $6000 \AA$ diameter) in ethylene glycol solvent, kindly

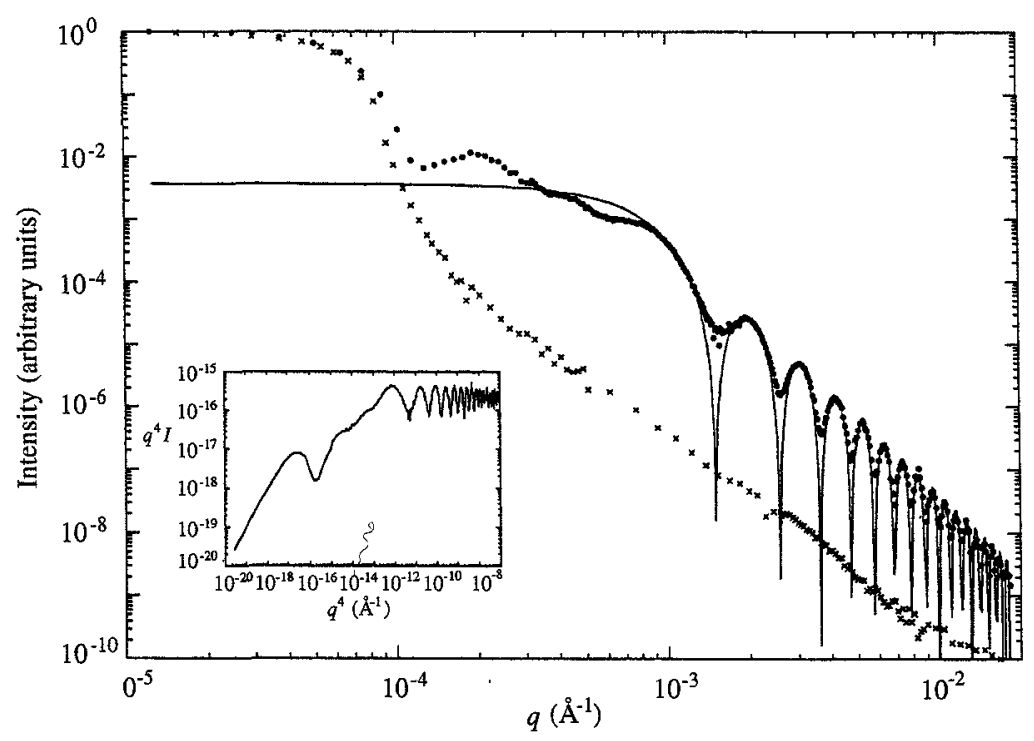

Fig. 3. Log-log plot of the scattering pattern (dotted line) from a silica sphere in an ethylene glycol liquid system $(15 \%$ in volume fraction, $6000 \AA$ diameter) recorded through the crossed analyers. The full line corresponds to theoretical form factor for a hard sphere with $6000 \AA$ diameter and the cross points correspond to the background (the rocking curve of $C 2$ ). In the inset, the data are plotted in $\left(q^{4}\right.$, $I q^{4}$ ) representation, making evident the mean slope of theform factor.

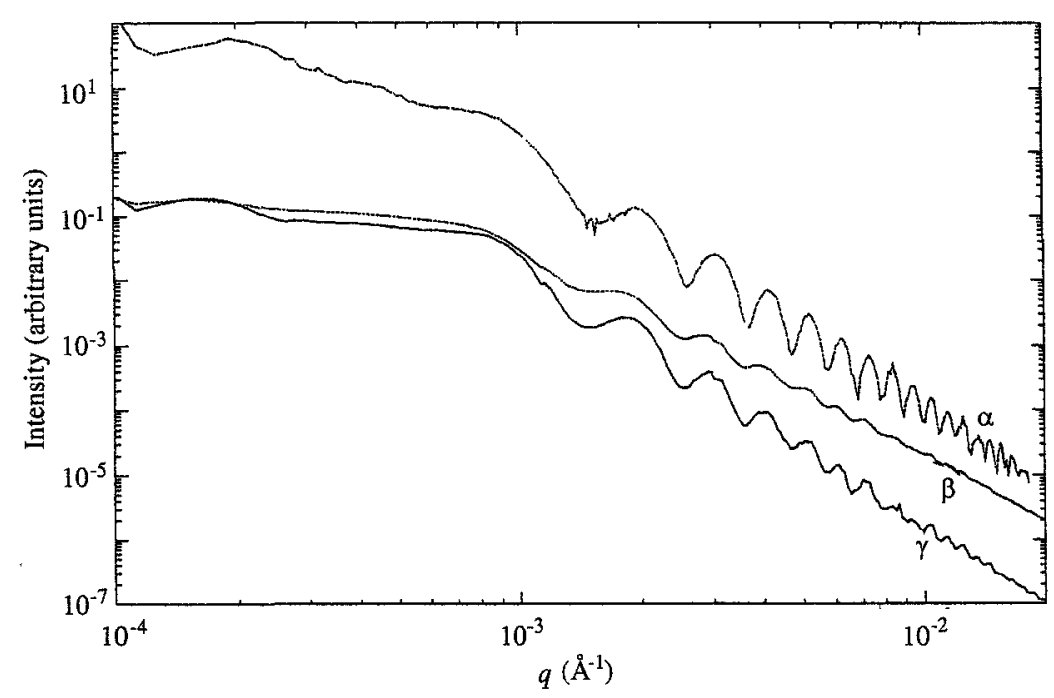

Fig. 4. Comparison between non-smeared $(\alpha)$, smeared $(\beta)$, and desmeared curves $(\gamma)$, obtained with two crossed analysers, one analyser + slit, and after the deconvolution operation, respectively. For the sake of intelligibility the curves have been offset by an arbitrary quantity. 
provided by Rhône-Poulenc Cie. With a very high resolution, we managed to reveal the intensity oscillations from the form factor of the spheres (oscillations at large $q$ values) and the liquid order (at ultra-low $q$ values). The raw data can be analysed without any deconvolution operation; the inset presents the same data in Porod representation. The black line corresponds to a fit of the form factor for monodispersed spheres with a diameter of $6000 \AA$. The three scattering-angle decades were covered in $5 \mathrm{~min}$ ( $1 \mathrm{~s}$ per point). The same experiment has been reproduced using configuration 1 (only one analyser crystal + vertical slits). The corresponding curve is displayed in Fig. 4 (curve $\beta$ ), making evident the smearing effect arising essentially from the vertical acceptance of the slits (compared to curve $\alpha$ ). A deconvolution operation was applied following the procedure described by Lambard et al. (1992), which considers a triangular folding function. The desmeared curve corresponds to curve $\gamma$ in Fig. 4 , and it is clear that the total information from the real scattering intensity (curve $\alpha$ ) has not been recovered. For the sake of intelligibility, all the curves have been offset by an arbitrary quantity.

The second silica system example concerns a zeolite system, a crystalline silica-alumina material with a well defined microporous structure. The sample was investigated during its crystallization process (Dokter, 1994). In general, zeolites may crystallize from an amorphous
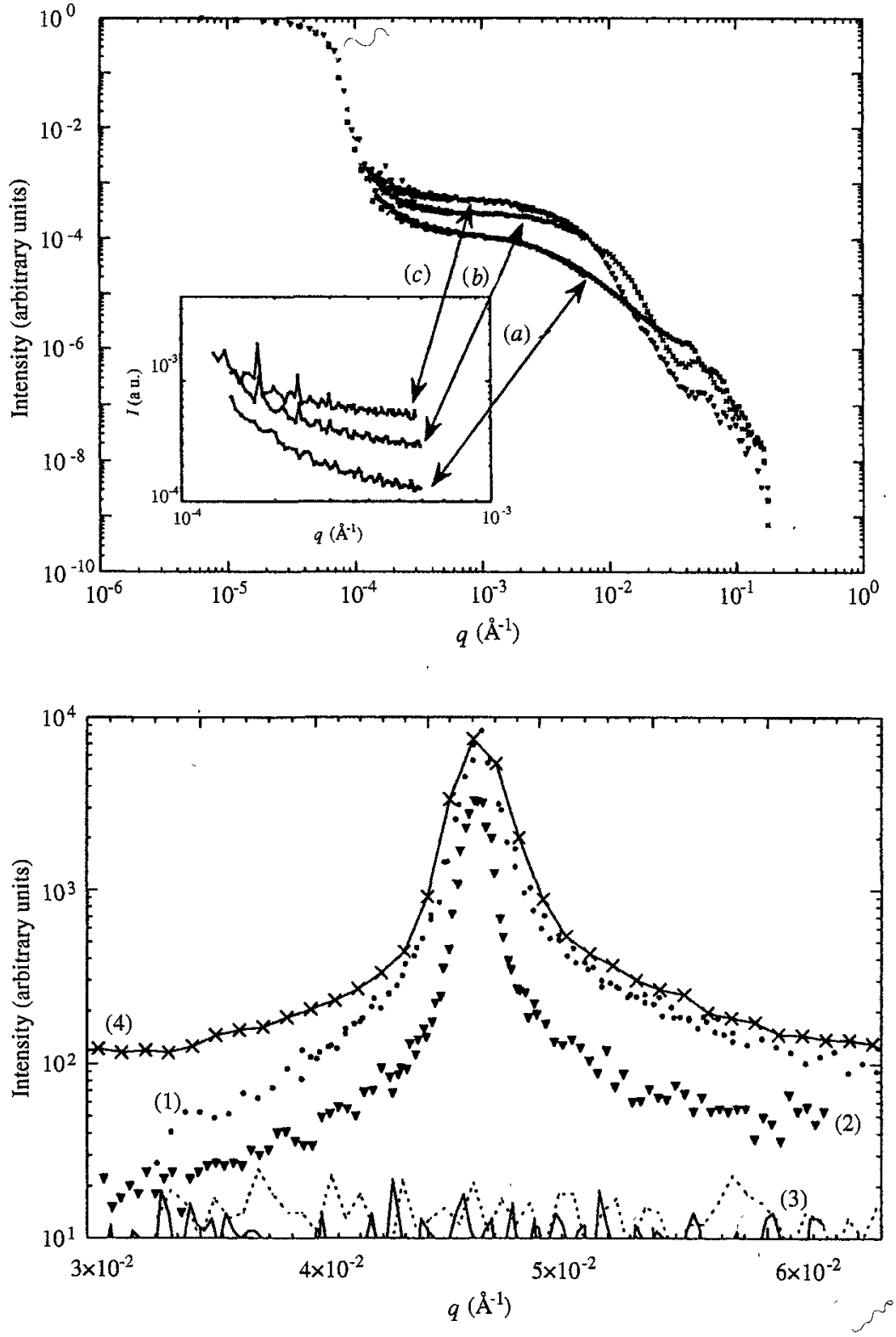

Fig. 5. SAXS patterns from a zeolite system recorded at different steps of the crystallization process: (a) at room temperature; $(b)$ at $433 \mathrm{~K}$ and $t=0 \mathrm{~s}$; (c) at $433 \mathrm{~K}$ and $t=3 \mathrm{~h}$. The inset corresponds to a zoom of the ultrasmall and $q$ range.

Fig. 6. Typical Bragg peak profiles (1st order): (2) from a lyotropic lamellar phase with a periodicity of $120 \AA ;$ (1) from the mixed lamellar phase and $20 \%$ of added polymer, between the membranes and with the same periodicity. (3) corresponds to the background. Curve (4) corresponds to the peak profile of the same mixed system and recorded on the standard two-dimensional camera with a gas-filled detector. 
precursor gel, which is heated in such a way that the duration of the process. is controlled by the $\mathrm{pH}$ of the solution. In this case, the necessity of investigating the $q$ range below the standard limit region $10^{-3}$ to $5 \times$ $10^{-3} \AA^{-1}$ is very stringent owing to the fractal aggregation observed in such a system. The evolution of these aggregates also needs to be followed during the crystallization process (in situ), which occurs within a few hours. Fig. 5 shows three different curves extracted from a series recorded every $10 \mathrm{~min}$ (Beelen, Bolt \& de Moor, 1996). The first one (a) corresponds to an amorphous precursor gel at room temperature. Curves $(b)$ and $(c)$ correspond to the same system heated at $433 \mathrm{~K}:(b)$ refers to the beginning of the crystallization and $(c)$ was obtained $3 \mathrm{~h}$ afterwards. The three decades of the $q$ range allow one to follow very precisely the size and shape evolution of the primary particles in the $10 \mathrm{~nm}$ range, the correlation length between these particles and scattering excess in the $100 \mathrm{~nm}$ range, and the crystallization of large aggregates (see the Bragg peaks between $10^{-4}$ and $10^{-3} \AA^{-1}$ displayed in the inset) in the $\mu \mathrm{m}$ range. We did only some rapid scans over the total scattering range but, in principle, there is the possibility of increasing the scan steps by a factor of 50 , which would allow the occurrence of the Bragg peaks to be solved much better at ultra-low scattering angles.

The second application shows the benefit of the highangular-resolution detection at larger scattering angles. Relevant information can be obtained by analysing the profile of the Bragg peaks or the crystal mosaicity in ordered systems (Snell et al., 1995; Ferrer, Hirschler, Roth \& Fontecilla-Camps, 1996; Roux \& Safinya, 1988; Safinya, Sirota, Roux \& Smith, 1989). This, however, requires a very high resolution and very stable angular Xray detection.

As an example, we have chosen to study the singular scattering around the Bragg peak profiles in some lyotropic lamellar phases in which different concentrations of polymer have been added. The analysis of the decay of such tails gives some quantitative information on the elasticity characteristics of this system of membranes. Curve (1) in Fig. 6 corresponds to a Bragg-peak profile for a lamellar phase with a lamellae periodicity of $120 \AA$ (Bouglet \& Ligoure, 1997). The second curve corresponds to the Bragg-peak profile of the lamellar phase with $20 \%$ (volume faction) polymer between the surfactant bilayers keeping the distance between the membranes constant. By analysing the decay of the Bragg peak tails we can obtain some quantitative information on the elastic constants of the smectic liquid crystal. Curve (3) corresponds to the background of the camera and curve (4) represents the Bragg-peak profile of the same lamellar phase mixed with polymer and obtained with the standard SAXS camera on the beamline (Bösecke \& Diat, 1997). The resolution difference between the two cameras can be clearly seen.

\section{Conclusion}

These examples are still under investigation and are presented as an indication of the possibilities offered by a high-angular-resolution camera installed on a high-brilliance beamline at a third-generation synchrotron. Several other tests have been performed on clays, large molecules such as asphaltene in toluene, as well as holograms in a polymer matrix, and all look very promising. A user group has already tested this set-up and appreciated the ease of use of this camera. It is obvious that the choice between this camera and a standard 2D camera depends on the specific needs of the experimental studies, i.e. high or low resolution $\Delta \theta / \theta, 1 \mathrm{D}$ or $2 \mathrm{D}$ detection, static or time-resolved experiments, small- or large-beam cross section, but the opportunity is given to use both systems on ID2 at the ESRF.

We are greatly indebted to J. Gorini, P. Wattecamps, J. Giovani and V. Rey Bakaikoa for providing quick solutions to many technical and computing problems. We are grateful to A. Paul and the optics group for providing the very good set of channel-cut crystals.

\section{References}

Arthur, J. (1996). Private communication.

Beelen, T. M. T., Bolt, D. H. \& de Moor, P. P. (1996). ESRFSC138 experiment. ESRF, Grenoble, France.

Bonse, U. \& Hart, M. (1965). Appl. Phys. Lett. 7, 238.

Bonse, U. \& Hart, M. (1966). Z. Phys. 189, 151.

Bonse, U., Pahl, R. \& Nusshard, R. (1988). Hasylab Annual Report, p. 326. Hasylab, Germany.

Bösecke, P., Diat, O. \& Rasmussen, B. (1995). Rev. Sci. Instrum. 66, 1636-1639.

Bösecke, P. \& Diat, O. (1997). J. Appl. Cryst. 30, 867-871.

Bouglet, G. \& Ligoure, C. (1997). In preparation.

Chapman, D., Hasting, J., Moulin, H., Siddons, D. P., Garrett, R. F., Nachaliel, E. \& Dilmanian, F. A. (1992). Nucl. Instrum. Methods, A319, 149.

Diat, O., Bösecke, P., Ferrero, C., Freund, A. K., Lambard, J. \& Heintzmann, R. (1995). Nucl. Instrum. Methods, A356, 566. Dokter, W. H. (1994). PhD thesis. Eindhoven University, The Netherlands.

Dumond, J. W. M. (1937). Phys. Rev. 52, 872.

Ferrer, J. L., Hirschler, J., Roth, M. \& Fontecilla-Camps, J. C. (1996). ESRF Newsletter, pp. 26-27.

Graf, H. A., Schneider, J. R., Freund, A. \& Lehmann, M. S. (1981). Acta Cryst. A37, 863.

Lambard, J., Lesieur, P. \& Zemb, T. (1992). J. Phys. I, 21, 1191. Pahl, R. (1990). PhD thesis, Dortmund University, Germany. Pahl, R. \& Bonse, U. (1995). J. X-ray Sci. Tech. 5, 368.

Roux, D. \& Safinya, C. R. (1988). J. Phys. (Paris), 49, 307.

Safinya, C. R., Sirota, C. R., Roux, D. \& Smith, G. S. (1989). Phys. Rev. Lett. 62, 1134.

Snell, E. H., Weissberger, S., Helliwell, J. R., Weckert, E., Hoelzer, K. \& Schroer, K. (1995). Acta Cryst. D51, 1099. 